\title{
The Influence of Pelvic Floor Fascial (Manual) Mobilization in Multiparous Women -A randomized controlled trial
}

\author{
Sivan Navot ${ }^{1}$, Eliezer Carmeli ${ }^{1}$, Aya Mohr-Sasson ${ }^{2}$, and Israel Hendler ${ }^{2}$ \\ ${ }^{1}$ University of Haifa Faculty of Social Welfare and Health Sciences \\ ${ }^{2}$ Tel HaShomer Hospital
}

August 11, 2020

\begin{abstract}
Objective Pelvic Floor Fascial Mobilization (PFFM) is an innovative intervention to improve pelvic floor dysfunction. Design Pregnant women at 24-30 weeks gestation, complaining of pelvic pain, and or stress urinary incontinence, were prospectively randomized to PFFM (study group) vs. pelvic floor muscle training (PFMT). Strength and function of the pelvic floor muscles was compared before and after interventions. Setting- Outpatient pregnancy clinic at a tertiary medical center Sample- 40 women randomly allocated to PFFM or PFMT Methods Each patient was treated twice, one week apart and was assessed immediately before and after each intervention, and one week after the second treatment. Main Outcome Measures PFDI 20 questionnaire, Oxford grading scale, perineometry to measure pelvic floor symptoms function and strength, transvaginal ultrasound cervical length Results PFFM group Oxford scale improved from $2.65 \pm 1.18$ to $3.45 \pm 1.28$ after the first session $(\mathrm{p}<0.001)$ with no difference in the PFMT group $3.40 \pm 1.05$ vs $3.40 \pm 1.05(\mathrm{p}=1)$. Cervical Length elongated in the PFFM group after one treatment $(39.8 \pm 6.5$ vs $43.4 \pm 10.2 \mathrm{~mm}, \mathrm{p}<0.05$, but not in the PFMT group $40.9 \pm 6.7$ vs $40.0 \pm 8.6$ respectively ( $\mathrm{p}=\mathrm{n} . \mathrm{s})$. Among 26 participants who lasted the entire study - PFMT was associated with more than $40 \%$ improvement in both Oxford as well as PFDI-20 and Perineometry was improved by $23 \%(23.13 \pm 15.15$ vs $28.58 \pm 16.07 \mathrm{cmH} 2 \mathrm{O}(\mathrm{p}<0.05)$ while no such difference was found with PFMT; $30.03 \pm 12.73$ vs $30.25 \pm 9.61 \mathrm{cmH} 2 \mathrm{O}$ respectively $(\mathrm{p}=\mathrm{n} . \mathrm{s}$ ). Conclusions PFFM may improve pelvic floor function and strength, alleviate symptoms and elongate the cervix. Further bigger study is needed to better evaluate this method.
\end{abstract}

The Influence of Pelvic Floor Fascial (Manual) Mobilization in Multiparous Women -A randomized controlled trial

Sivan Navot ${ }^{1}$, Eliezer Carmeli $^{1}$, Aya Mohr-Sasson ${ }^{2,3}$, Israel Hendler ${ }^{2,3}$

1. Physical Therapy Department, Haifa University, Haifa, Israel

2. Department of Obstetrics and Gynecology, Sheba Medical Center, Ramat-Gan, Israel

3. Sackler School of Medicine, Tel-Aviv University, Tel-Aviv, Israel

Corresponding author:

Sivan Navot

Email: sivan.navot@gmail.com

Tel: +972-54-2808666

Short Title : Pelvic Floor Fascial (Manual) Mobilization in Multiparous Women

Tweetable abstract 
Vaginal fascial mobilization can improve pelvic floor dysfunction and cervical length in pregnant women.

Abstract

Objective Pelvic Floor Fascial Mobilization (PFFM) is an innovative intervention to improve pelvic floor dysfunction. Design Pregnant women at 24-30 weeks gestation, complaining of pelvic pain, and or stress urinary incontinence, were prospectively randomized to PFFM (study group) vs. pelvic floor muscle training (PFMT). Strength and function of the pelvic floor muscles was compared before and after interventions. Setting- Outpatient pregnancy clinic at a tertiary medical center Sample- 40 women randomly allocated to PFFM or PFMT Methods Each patient was treated twice, one week apart and was assessed immediately before and after each intervention, and one week after the second treatment. Main Outcome Measures PFDI 20 questionnaire, Oxford grading scale, perineometry to measure pelvic floor symptoms function and strength, transvaginal ultrasound cervical length

Results

PFFM group Oxford scale improved from $2.65 \pm 1.18$ to $3.45 \pm 1.28$ after the first session $(\mathrm{p}<0.001)$ with no difference in the PFMT group $3.40 \pm 1.05$ vs $3.40 \pm 1.05(\mathrm{p}=1)$. Cervical Length elongated in the PFFM group after one treatment $(39.8 \pm 6.5$ vs $43.4 \pm 10.2 \mathrm{~mm}, \mathrm{p}<0.05$, but not in the PFMT group $40.9 \pm 6.7$ vs $40.0 \pm 8.6$ respectively $(\mathrm{p}=\mathrm{n} . \mathrm{s})$.

Among 26 participants who lasted the entire study - PFMT was associated with more than $40 \%$ improvement in both Oxford as well as PFDI-20 and Perineometry was improved by $23 \%$ (23.13 \pm 15.15 vs $28.58 \pm 16.07$ $\mathrm{cmH}_{2} \mathrm{O}(\mathrm{p}<0.05)$ while no such difference was found with PFMT; $30.03 \pm 12.73$ vs $30.25 \pm 9.61 \mathrm{cmH}_{2} \mathrm{O}$ respectively $(\mathrm{p}=\mathrm{n} . \mathrm{s})$.

Conclusions

PFFM may improve pelvic floor function and strength, alleviate symptoms and elongate the cervix. Further bigger study is needed to better evaluate this method.

Funding (To include the name of the funding body and the grant identifier)

No funding was granted for this trial

Key Words : Pelvic floor, Manual Therapy, Pregnancy, Cervical Length

Introduction

Pregnancy and birth are considered as the main risk factors for damage to the pelvic floor structure and function. The damage may appear as stress incontinence, fecal incontinence, pelvic organ prolapses, pelvic and low back pain or urination and defecation difficulties. Each pregnancy may intensify the damage and the symptoms become more severe as gestation advances ${ }^{1-9}$.

The different modalities of treatment for pelvic floor dysfunction; includes physiotherapy for Pelvic Floor Muscle Training (PFMT), perineal massage or manual techniques ${ }^{10}$.

PFMT have shown promising results with improvement in urinary stress incontinence (UI), after an intensive intervention program that lasts an average of 8 to 24 weeks $^{11}{ }^{12}$, In a Cochrane database review of 31 trials, the authors concluded that PFMT could be part of a first line conservative management program for women with UI. PFMT can also be used as a preventive mode of treatment during pregnancy with moderate results. Recently, a Cochrane review of 46 trials, provided evidence that PFMT in early pregnancy for continent women may prevent the onset of UI in late pregnancy and postpartum ${ }^{13}$. However, prolonged and continuous exercise as well as compliance and perseverance are needed in order to achieve satisfactory results $^{14}$.

Manual technique for the pelvic floor musculature is an optional treatment modality ${ }^{15-20}$, Antenatal digital perineal massage was shown to reduce the likelihood of perineal trauma (mainly episiotomies), the reporting 
of ongoing perineal pain, and is generally well accepted by women ${ }^{21}$. Perineal trauma and levator muscle injury are one of the major causes of pelvic floor dysfunction after childbirth. However, neither the effectiveness of manual treatment for pelvic floor dysfunction nor the influence on possible adverse effects to the pregnancy, such as cervical shortening, preterm birth, or blood flow to the fetus, was well investigated by randomized controlled trials. In fact, the influence of manual therapy is unknown, and most of the literature is dedicated to PFMT, and mainly for postpartum rehabilitation.

Pelvic Floor Fascial Mobilization (PFFM) is an innovative intra vaginal and / or intra rectal manual therapy technique developed (by S.N.) to treat pelvic fascial dysfunction by improving fascial gliding. Treatment of fascia may improve muscle function. ${ }^{22}$ Fascial scar release techniques by soft tissue mobilization have shown improvements for treatment of abdominal and pelvic adhesions related pain. ${ }^{23}$

This is a pioneer study comparing the influence of PFFM vs. conventional PFMT on the function and strength of the pelvic floor muscles, in $2^{\text {nd }}$ and $3^{\text {rd }}$ trimester pregnant women with pelvic floor dysfunction. The primary outcome was the pelvic floor strength before and after treatment in each group. Secondary outcomes included: Umbilical Artery (UmbA) blood flow, uterine artery (UA) blood flow, fetal Middle Cerebral Artery (MCA) flow, and cervical length (CL).

Materials and Methods

A prospective randomized unblinded controlled trial performed between January 2018 and July 2019, at an outpatient pregnancy clinic in a single tertiary medical center. We enrolled primiparous and multiparous pregnant women at 24-30 weeks gestation, with symptoms related to pelvic floor dysfunction.

Exclusion criteria included: First delivery, Gestational age $>30$ weeks gestation at enrollment, Premature contractions, Cervical shortening, Placenta previa, Placenta accreta, Multifetal pregnancy, Maternal connective tissue disease and neurological illness.

Sample size was calculated based on an $\alpha$-error of $5 \%$, with a power of $80 \%$, based on the assumption that PFFM will improve pelvic floor strength and function by $30 \%$, compared to control. Randomization was done with the "Randomizer.org" ${ }^{24}$ based on two random sets of numbers from 1-20. The allocation of each number to study or control group was in an envelope by the

Research facilitator (I.H.) The patient received the ordinal number for participation upon signing the informed consent, from the main researcher (S.N) based on the chronological assignment to the study. The main researcher was blinded to the association between the chronological number and the study group allocation prior to the initialization of the intervention for each patient.

Each patient was treated twice during the study period, one to two weeks apart and was assessed five times: immediately before and after each intervention, and one week after the second treatment session.

During the first and fifth assessment women were evaluated for pelvic floor dysfunction using PFDI-20 questionnaire (pelvic floor disability index-20) validated in Hebrew. Pelvic muscle strength and function was assessed 5 times using Oxford Grading Scale, modified by Laycock ${ }^{25}$, that includes 6 levels (0-5) and by a Perineometer device ${ }^{7}$ (Peritron ${ }^{\text {tm }}$ Vaginal Perineometer ,Cardio-Design, Australia). Both Oxford scale and the Perineometer are considered efficient and well correlated with the use of surface electro myography (SEMG) that present the level of the muscle electrical activity ${ }^{26-28}$.

Uterine and fetal blood flow was assessed 5 times as well, before and after each intervention and one week after the second intervention. All measurements were performed by the operator who was blinded to study allocation. Abdominal ultrasound was used to measure: Uterine Artery (UA) blood flow pulsatility index (PI), umbilical artery (UmbA) blood flow PI and Middle cerebral artery (MCA) PI, uterine Cervical Length (CL) was measured by transvaginal ultrasound from the internal to external cervical os (Voluson P6, General Electric Inc. USA).

Pelvic Floor Facial Mobilization is a manual therapy based upon the sequences and movement planes of Stecco's Fascial Manipulation $\left(\mathbb{R}\right.$. technique ${ }^{29-33}$ relying on similar main principles of treating fascial densifica- 
tions along pre-defined routs. According to Stecco's method, the body is divided to different segments, each includes Myofascial units (MFU) that belong to different movement planes. Embedded in each myofascial unit are centers of perception (CP), centers of coordination (CC), and centers of fusion (CF). Myofascial units in the same plane of movement creates a myofascial sequence. ${ }^{29-33}$

Centers of Fusion (CF) are the converging points of the vectors for every two adjacent MFUs and are responsible for coordinating the movements in intermediate directions between the two planes. CFs are principally located over the retinacula surrounding the joints ${ }^{29-31}$. Since the key fascial areas (CCs) are different than the areas where pain or symptoms are perceived (CPs), treatment is applied at a distance, away from the painful area which is advantageous in management of pain ${ }^{34} 35$.

The centers of coordination (CC's) and centers of fusions (CF's) in the pelvic floor region are presented in figure 1,36

\section{PFFM Treatment model}

Points of treatment were chosen according to the anamnesis (previous history of trauma, operations, birth complications, etc.), observation of pelvic floor muscular dysfunction and palpation of fascial densification in a relevant CC's or CF's.

The manual technique included gliding like friction, over the densified fascial points in an opposite direction to the tension line of the tissue and in combination with the active motion of the hip joint in the following order: full flexion-abduction-external, rotation-extension-adduction-flexion. The hip movement changes the multi-directional tension of the tissues involved and helps achieve a smooth gliding movement between the fascia layers ${ }^{32} 37-41$.

Women were randomly assigned to two treatment groups:

Group A-Study group (n=20)

PFFM was provided for $40 \mathrm{~min}$, involving intra vaginal as well as external pelvic area $\mathrm{CF}$ and $\mathrm{CC}$ points. The manipulation did not involve the cervix, uterus, or rectum.

Group B-Control group ( $n=20)$

Exercise session with personal guidance of PFMT provided for 40 min. based on a protocol for physiotherapy training of the pelvic floor adopted from Salvesen \& MØrkved ${ }^{42}$. Women were instructed to perform 2 sets of 8-12 near maximal pelvic floor muscle contractions and hold the contraction for 6-8 seconds. At the end of each contraction the women were asked to add three to four fast contractions. The resting period was 12 seconds. training was performed in lying and sitting positions. In addition, the women were instructed to repeat the exercise at home twice a day.

All participants in both groups were assessed immediately post intervention for Oxford scale measurement, Perineometry, Ultrasound measurements of UA, UmbA and MCA PI's and CL.

One week after the first session, reassessment of all the participants prior to second intervention and repeat treatment and exercise were performed. After two more weeks participants fifth evaluation and completion of PFDI-20 for the second time were performed.

Flow chart of study randomization, patient allocation and Data analysis is described in Figure 6

Statistical analysis

Normality of the data was tested using the Shapiro-Wilk or Kolmogorov-Smirnov tests. Categorical variables are described as frequency and percentage. continuous variables are described using either mean and standard deviation or median and interquartile range. Categorical variables were compared using the Chi square test.

A Two-Way Repeated Measures analysis as well as ANOVA mixed design was performed:

1) Before and after the manipulation at the first session, 
2) Throughout the five measurements,

A Pair Sample t-Test was conducted for each group separately.

Significance accepted at $\mathrm{p}<0.05$. IBM Statistical Package for the Social Sciences (IBM SPSS v.21; IBM Corporation Inc, Armonk, NY, USA).

Results

40 women who complained of symptoms associated with pelvic floor dysfunction were enrolled and randomized, ${ }^{43} 20$ in each group. The median: age, gravidity, parity, BMI, and gestational age were similar between groups (table 1). Study group had a weaker pelvic floor muscles at enrollment. The average Oxford scale was $2.7 \pm 1.2$ in the study group vs. $3.4 \pm 1.0$ in the control $(\mathrm{p}<0.05)$. perineometry was $22.0 \pm 15.0$ vs. $29.4 \pm 12.3 \mathrm{cmH}_{2} \mathrm{O}$ respectively $(\mathrm{p}<0.086)$

However, prior to intervention, there was no difference in the severity of symptoms as tested by PFDI-20: $27.1 \pm 12.2$ vs. $26.0 \pm 13.5$ points respectively in the study vs control group ( $\mathrm{p}=0.7)$.

After the first session, Oxford test in the study group improved from $2.7 \pm 1.2$ to $3.5 \pm 1.3$ ( $\mathrm{p}<0.001$ ) while no difference was shown in the control group $3.4 \pm 1.0$ vs $3.4 \pm 1.1(\mathrm{p}=1)$.

The perineometry measurements, were marginally improved in the study group $22.0 \pm 14.4$ vs $24.6 \pm 17.5$ $(\mathrm{p}=0.075)$. With no difference in the control group $29.4 \pm 12.3$ vs $30.1 \pm 12.5(\mathrm{p}=\mathrm{n} . \mathrm{s})$. We found positive correlation between perineometry measurements and Oxford grading scale before $(\mathrm{r}=0.73)$ and after intervention $(\mathrm{r}=0.69)$ in both study and control groups $\mathrm{P}<0.001$.

Uterine artery pulsatility Indexes (PI) measurement were decreased when compared before and after the first treatment, in both groups. There was no difference in Umbilical Artery flow.

Cervical Length elongated in the study group after the first treatment (39.8 \pm 6.5 vs $43.4 \pm 10.2 \mathrm{~mm}$ respectively, $\mathrm{p}<0.05$. while $\mathrm{CL}$ in the control group was $40.9 \pm 6.7$ vs $40.0 \pm 8.6$ before and after exercise respectively $(\mathrm{p}=\mathrm{n} . \mathrm{s})$.

26 participants complied with the entire study protocol, were treated twice, and assessed 5 times (before and after the first and second session and two weeks after the second session) and ended the study.

Among the 16 (80\%) participants of the study group who completed the study, the oxford scale at enrollment was $2.6 \pm 1.2$ and increased to $3.85 \pm 1.1$ at the fifth evaluation $(\mathrm{p}<0.05)$, while in the $10(50 \%)$ participants of the control group it was $3.4 \pm 1.1$ vs. $3.9 \pm 1.0(\mathrm{p}<0.05)$. There was $42.5 \%$ improvement in Oxford scale for the study group vs $14.7 \%$ for the control group. (figure 2, )

Although perineometry measurements were superior in the control group prior to the study, as well as at the end of the study, there was an improvement in the pelvic floor strength compared within each group before and after the study. Perineometry measurements were improved in the study group from enrollment to the fifth evaluation by $23 \%\left(23.1 \pm 15.2\right.$ vs $28.6 \pm 16.1 \mathrm{cmH}_{2} \mathrm{O}$ respectively $(\mathrm{p}<0.05)$ while no difference was found between the first and the fifth evaluation in the control group $30.0 \pm 12.7$ vs $30.3 \pm 9.6 \mathrm{cmH}_{2} \mathrm{O}$ respectively ( $\mathrm{p}=$ n.s) (figure 3).

There were no differences in PI of the UA, UmbA, and MCA PI in both groups.

There was no difference between the first and the fifth measurement of CL $(40.54 \pm 6.91$ vs $39.88 \pm 8.91 \mathrm{~mm}$ in the study group, and $42.23 \pm 6.87$ vs $42.30 \pm 7.39 \mathrm{~mm}$ in the control group, respectively, ( $\mathrm{p}=\mathrm{n} . \mathrm{s})$ (figure 4 ) 
PFDI-20 showed significant improvement: in the study group it was reduced from $27.8 \pm 12.5$ to $19.3 \pm 10.8$ ( $42 \%$ improvement) and in the control group from $22.6 \pm 16.4$ to $20.1 \pm 13.7$ (12\% improvement) $\mathrm{p}=0.001$ for both groups. (figure 5)

There were no cases of cervical shortening, decreased blood flow to uterus or fetus, preterm birth or vaginal bleeding in the study or control groups.

None of the patients had preterm birth vaginal bleeding or described any adverse effects due to the intervention methods

\section{Discussion}

Principal findings : This is the first study to evaluate the effect of manual fascial mobilization treatment in comparison to pelvic floor muscle training for pregnant women. We found that the technique used was safe. Both the study and the control group included participants with mild to moderate pelvic floor dysfunction , both groups were similar in their demographical characteristics, while, perineometry measurements were superior in the control group prior to the study, it was improved in the study group from enrollment to the fifth evaluation by $23 \%$ while no difference was found in the control group. We were able to show that the treatment group had better results after one, as well as after two sessions, compared to the control group, in both Oxford test, cervical length, and perineometry. There was better compliance to end the study in the PFFM group compared to the controls, and there was more than $40 \%$ improvement in both Oxford as well as PFDI-20 in the longitudinal evaluation for 16 participants who lasted the entire PFFM study group vs, $10-14 \%$ improvement in the control group.

Results : The validity of our results can be shown in a comparison to the study by Caroci et al ${ }^{8}$ who analyzed 220 gravidas. The average perineometry PFMS was $33.4 \pm 21.2 \mathrm{cmH}_{2} \mathrm{O}$. We found similar measurements in the control group, $(29.40 \pm 12.32)$ and lower in the study group $\left(21.95 \pm 14.95 \mathrm{cmH}_{2} \mathrm{O}\right)$. The median Oxford scale in our study was 3.0 in the control group vs. 3.5 in the study group, similarly, Resende at $\mathrm{al}^{44}$ found an average of $2.1 \pm 0.9$ of Oxford scale among 15 primiparous. Patricelli et al ${ }^{28}$ reported an average of $2.53 \pm 0.57$ among nulliparous.. Thus, the Oxford in the control group was similar to that described elsewhere, while the study group had weaker pelvic floor muscles.

We found positive correlation between Perinometer measurements and Oxford grading scale before and after intervention in both study and control groups (table 2), similarly, Da Roza et al ${ }^{45}$ described a positive correlation between Oxford scale and Perineometry in pregnant women as well as Batista et $\mathrm{al}^{7}$ and Gameiro et $\mathrm{al}^{46}$.

We found PFDI-20 of $27.1 \pm 12.2$ vs. $26.0 \pm 13.5$ respectively in the study vs. control group in second trimester women, prior to intervention, $(\mathrm{p}=0.7)$ similar to the results by Martinez $\mathrm{F}$. et $\mathrm{al}^{47}$ in which women in the third trimester had a PFDI-20 score of 32.77 and 20.83 in the first trimester.

The positive effect of PFMT was shown by Boyle et al ${ }^{11}{ }^{12}$ In a Cochrane meta-analysis of 22 trials involving 8,485 women. Continent women who had intensive antenatal pelvic floor muscle training were less likely to report urinary incontinence post-partum. Davenport et $\mathrm{al}^{48}$ published a metanalysis of 24 studies including 15,982 women. PFMT decreased the odds of UI in pregnancy (15 randomized controlled trials (RCTs), $\mathrm{n}=2764$ women; OR $0.50,95 \%$ CI 0.37 to $0.68, \mathrm{I} 2=60 \%)$ and in the postpartum period $(10 \mathrm{RCTs}, \mathrm{n}=1682$ women; OR $0.63,95 \%$ CI $0.51,0.79, \mathrm{I} 2=0 \%$ ). Schreiner et $\mathrm{al}^{49}$ published a metanalysis of 22 trials that compared EPI-NO perineal dilator (Tecsana, Munich, Germany), pelvic floor muscle training, and perineal massage with a significant reduction in the duration of the second stage of labor $(\mathrm{P}<0.01)$, and decreased incidence of urinary incontinence. Similarly, in our study PFMT showed benefit on pelvic floor symptoms and strength. However, the improvement measured after PFFM was superior. We have found $10-15 \%$ improvement in Oxford scale, perineometry and PFDI-20 with PFMT vs more than $40 \%$ improvement when PFFM was used. Moreover, even though women in the study group had a weaker pelvic floor prior to study intervention, the results of Oxford scale and Perineometer were similar after intervention in both groups. 
Pulsatility Indexes (PI) measurements of the uterine arteries are a parameter for uterine blood supply ${ }^{50} 51$. Increased PI of the Ut artery during the third trimester was found to be associated with intra-uterine growth restriction of the fetus ${ }^{52}$. In our study the PI of the UA UmbA MCA was unchanged when compared before and after treatment in the study group as well as in the controls.

Okido et al ${ }^{53}$ examined the PI's of MCA, UA and UmbA in 96 women who were randomized to intervention $(n=26)$ with daily PFMT program vs no intervention $(n=33)$. Results showed normal values of the PI's of both UA, MCA and UmbA, with no difference between groups. Measurements performed at 28 and 32 weeks of gestation, showed no impact of treatment on resistance to flow as measured by uterine artery PI. Similarly, in our study performed between 24-32 weeks, the PI's of the UA as well the UmbA and MCA did not change before and after treatment.

Cervical Length elongated after the first treatment in the study group $(39.8 \pm 6.5$ vs $43.4 \pm 10.2 \mathrm{~mm}$ respectively $\mathrm{p}<0.05)$. while no difference was found in the controls $(40.9 \pm 6.7$ vs $40.0 \pm 8.6$ before and after exercise respectively $\mathrm{p}=\mathrm{n} . \mathrm{s}$ ). In the longitudinal measurement we found no effect of treatment for both groups.

Many etiologies have been postulated for the shortening of the cervical length during pregnancy, including primary cervical insufficiency, inflammation and infectious processes, genetic etiology, and others. Aran et $\mathrm{al}^{54}$ recently presented that a short cervix can be due to weak pelvic floor muscles, and thus elongation of cervical length may be achieved by improving the pelvic floor muscular function and strength through better gliding of the fascia.

Clinical implications Pelvic Floor Fascial Mobilization (PFFM) is an innovative manual technique for treatment of pelvic floor dysfunction by improving fascial gliding. The connective (Fascial) tissues form a ubiquitous network throughout the whole body, which is usually regarded as a passive contributor to biomechanical behavior of muscles and organs. Treatment of fascia may improve muscle function. ${ }^{22}$ Fascial scar release techniques by soft tissue mobilization have shown improvements for treatment of abdominal and pelvic adhesions related pain. ${ }^{23}$

PFFM is an intra vaginal and / or intra rectal manual therapy technique developed (by S.N.) to treat pelvic fascial dysfunction, continuous to the total outer body Fascial manipulation ${ }^{\circledR}$ technique developed by Stecco ${ }^{29-31} 33$. PFFM was shown to rapidly improve pelvic floor function in a male cyclist involved in an accident after only two, 40 minutes intervention sessions ${ }^{36}$ Treatment of fascia may improve muscle strength, ${ }^{22}$ and by PFFM, the pelvic floor musculature could gain proper strength and a balanced tone. PFFM was associated with an improvement of PFM strength by more than $40 \%$ as well as reducing subjective symptoms by more than $40 \%$. Such improvement was not found for pelvic floor exercise

PFFM can benefit cervical length as well. Anatomically, the cardinal and the uterosacral ligaments provide extensive attachment of the cervix to the lateral pelvic walls, the greater sciatic foramen, the piriformis, and the lateral sacrum, as far as the sacroiliac joints. The uterosacral ligaments are attached to the cervix postero-laterally, and posteriorly to the fascia in front of the sacroiliac joints ${ }^{55} 56$. The apex of the vagina and uterus are held in place by the uterosacral and cardinal ligaments, anchoring the cervix over the levator plate. This 3-dimensional fascial-ligamentous creates a cradle-like structure holding the cervix in its proper position.

This may lead to better and equal support of the ligamentous structures, and hence, change the tension applied on the cervix, and contribute to its length and endurance. We found when an elongation of the CL measured on 20 participants after treatment with PFFM with no effect of regular pelvic exercise. Research implications : We present a possible innovative and safe method for the treatment of pelvic floor disorders in pregnant women is investigated. Further study is needed on a larger sample size to evaluate the effect of PFFM on elongation of cervical length during pregnancy and to evaluate the effect of PFFM on prevention and treatment of urinary incontinence. 


\section{Strengths and limitations}

Strengths: 1. A pioneer randomized controlled study performed by a single operator with strict implementation of the exact same PFFM method. 2. The high correlation between the subjective measurements via perineometer and the objective measurement of pelvic strength via Oxford grading scale in both groups validate our results. Limitations: 1 . A small sample size and due to moderate compliance only 26 out of 40 participants completed the study. 2. The assessment of the majority of patients in both groups was done by the main researcher, which can affect the objectivity of the measurements. However, each measurement was performed independently and separately while the analysis and the comparison of the results was only done at the end of the study. Moreover, the results of the measurements performed by the researcher agree with PFDI-20 questionnaire results filled by the participants. We had positive effect for the PFFM, and our results, where manual therapy is shown to improve muscle and joint function are in agreement with the existing data in the literature ${ }^{57}$. 3. There was a basal difference in the strength of the pelvic floor between the treatment and the control group which made the comparison cumbersome. However, most of our tests applied an intra group benefit for the treatment method.

- The authors report no conflict of interests

- Contribution to Authorship:

N. S.-Planning, carrying out, analyzing and writing

M.S.A-Planning, carrying out

C.E- Planning, analyzing

H.I- Planning, carrying out, analyzing and writing

The study was approved by the IRB of the Sheba Medical Center, (3722-16-SMC) on February $14^{\text {th }} 2017$. NIH registry. (approval no. NCT03041246). Full trial protocol is available at the NIH registry.First Posted: February 2, 2017, First enrollment: January 1, 2018

No funding was granted for this trial

References

1. Hallock JL, Handa VL. The Epidemiology of Pelvic Floor Disorders and Childbirth: An Update. Obstet Gynecol Clin North Am2016;43(1):1-13. doi: 10.1016/j.ogc.2015.10.008 [published Online First: 2016/02/18]

2. Van Veelen GA, Schweitzer KJ, van der Vaart CH. Ultrasound imaging of the pelvic floor: changes in anatomy during and after first pregnancy. Ultrasound in obstetrics $\& 5$ gynecology : the official journal of the International Society of Ultrasound in Obstetrics and Gynecology2014;44(4):476-80. doi: 10.1002/uog.13301

3. Rikard-Bell J, Iyer J, Rane A. Perineal outcome and the risk of pelvic floor dysfunction: a cohort study of primiparous women.Aust N Z J Obstet Gynaecol 2014;54(4):371-6. doi: 10.1111/ajo.12222

4. Webb S, Sherburn M, Ismail KM. Managing perineal trauma after childbirth. BMJ 2014;349:g6829. doi: 10.1136/bmj.g6829

5. Klein MC, Gauthier RJ, Robbins JM, et al. Relationship of episiotomy to perineal trauma and morbidity, sexual dysfunction, and pelvic floor relaxation. American Journal of Obstetrics and Gynecology1994;171(3):591-98. doi: 10.1016/0002-9378(94)90070-1

6. Eason E, Labrecque M, Marcoux S, et al. Anal incontinence after childbirth. CMAJ 2002;166(3):326-30.

7. Batista EM, Conde DM, Do Amaral WN, et al. Comparison of pelvic floor muscle strength between women undergoing vaginal delivery, cesarean section, and nulliparae using a perineometer and digital palpation. Gynecol Endocrinol 2011;27(11):910-4. doi: 10.3109/09513590.2011.569603 
8. Caroci Ade S, Riesco ML, Rocha BM, et al. Evaluation of perineal muscle strength in the first trimester of pregnancy. Rev Lat Am Enfermagem 2014;22(6):893-901. doi: 10.1590/0104-1169.3600.2492

9. Dietz HP. Pelvic floor trauma in childbirth. Aust N Z J Obstet Gynaecol 2013;53(3):220-30. doi: 10.1111/ajo.12059

10. Hall H, Cramer H, Sundberg T, et al. The effectiveness of complementary manual therapies for pregnancy-related back and pelvic pain: A systematic review with meta-analysis. Medicine (Baltimore) 2016;95(38):e4723. doi: 10.1097/MD.0000000000004723

11. Boyle R, Hay-Smith EJ, Cody JD, et al. Pelvic floor muscle training for prevention and treatment of urinary and faecal incontinence in antenatal and postnatal women. Cochrane Database Syst Rev2012;10:CD007471. doi: 10.1002/14651858.CD007471.pub2

12. Boyle R, Hay-Smith EJ, Cody JD, et al. Pelvic floor muscle training for prevention and treatment of urinary and fecal incontinence in antenatal and postnatal women: a short version Cochrane review.Neurourol Urodyn 2014;33(3):269-76. doi: 10.1002/nau.22402

13. Woodley SJ, Lawrenson P, Boyle R, et al. Pelvic floor muscle training for preventing and treating urinary and faecal incontinence in antenatal and postnatal women. Cochrane Database Syst Rev2020;5:CD007471. doi: 10.1002/14651858.CD007471.pub4 [published Online First: 2020/05/08]

14. Bo K, Haakstad LA. Is pelvic floor muscle training effective when taught in a general fitness class in pregnancy? A randomised controlled trial. Physiotherapy 2011;97(3):190-5. doi: 10.1016/j.physio.2010.08.014

15. FitzGerald MP, Kotarinos R. Rehabilitation of the short pelvic floor. I: Background and patient evaluation. Int Urogynecol J Pelvic Floor Dysfunct 2003;14(4):261-8. doi: 10.1007/s00192-003-1049-0 [published Online First: 2003/10/08]

16. FitzGerald MP, Kotarinos R. Rehabilitation of the short pelvic floor. II: Treatment of the patient with the short pelvic floor.Int Urogynecol J Pelvic Floor Dysfunct 2003;14(4):269-75; discussion 75. doi: 10.1007/s00192-003-1050-7 [published Online First: 2003/10/08]

17. Wallace SL, Miller LD, Mishra K. Pelvic floor physical therapy in the treatment of pelvic floor dysfunction in women. Curr Opin Obstet Gynecol 2019;31(6):485-93. doi: 10.1097/GCO.0000000000000584 [published Online First: 2019/10/15]

18. Oyama IA, Rejba A, Lukban JC, et al. Modified Thiele massage as therapeutic intervention for female patients with interstitial cystitis and high-tone pelvic floor dysfunction. Urology 2004;64(5):862-5. doi: 10.1016/j.urology.2004.06.065 [published Online First: 2004/11/10]

19. Weiss JM. Pelvic Floor Myofascial Trigger Points: Manual Therapy for Interstitial Cystitis and the Urgency-Frequency Syndrome. Journal of Urology 2001;166(6):2226-31. doi: 10.1016/s0022-5347(05)65539-5

20. Grewar H, McLean L. The integrated continence system: a manual therapy approach to the treatment of stress urinary incontinence.Man Ther 2008;13(5):375-86. doi: 10.1016/j.math.2008.01.003 [published Online First: 2008/03/15]

21. Beckmann MM, Stock OM. Antenatal perineal massage for reducing perineal trauma. Cochrane Database Syst Rev 2013(4):CD005123. doi: 10.1002/14651858.CD005123.pub3

22. Schleip R, Gabbiani G, Wilke J, et al. Fascia Is Able to Actively Contract and May Thereby Influence Musculoskeletal Dynamics: A Histochemical and Mechanographic Investigation. Front Physiol2019;10:336. doi: 10.3389/fphys.2019.00336 [published Online First: 2019/04/20]

23. Wong YY, Smith RW, Koppenhaver S. Soft Tissue Mobilization to Resolve Chronic Pain and Dysfunction Associated With Postoperative Abdominal and Pelvic Adhesions: A Case Report. J Orthop Sports Phys Ther 2015;45(12):1006-16. doi: 10.2519/jospt.2015.5766 [published Online First: 2015/10/17] 
24. Urbaniak G. C. PS. Research Randomizer. 4.0 ed, 2013.

25. Laycock J WM, Dumoulin C. Therapeutic management of incontinence and pelvic pain. In: Haslam J LJ, ed. 2nd ed. London: Springer 2008:57-66.

26. Laycock J, Jerwood D. Pelvic Floor Muscle Assessment: The PERFECT Scheme. Physiotherapy 2001;87(12):631-42. doi: 10.1016/s0031-9406(05)61108-x

27. Ribeiro Jdos S, Guirro EC, Franco Mde M, et al. Inter-rater reliability study of the Peritron perineometer in pregnant women.Physiother Theory Pract 2016;32(3):209-17. doi: 10.3109/09593985.2015.1129654

28. Petricelli CD, Resende AP, Elito Junior J, et al. Distensibility and strength of the pelvic floor muscles of women in the third trimester of pregnancy. Biomed Res Int 2014;2014:437867. doi: 10.1155/2014/437867

29. Stecco L. Fascial Manipulation for Musculoskeletal Pain. Padova: Piccin 2004:251.

30. Day JA CL, Rucli G. From clinical experience to a model for the human fascial system. Journal of Bodywork and Movement Therapies2012;16:372-80.

31. Stecco L SC. Fascial Manipulation Practical Part. Padova: Piccin 2009.

32. Stecco C, Day JA. The fascial manipulation technique and its biomechanical model: a guide to the human fascial system. Int $J$ Ther Massage Bodywork 2010;3(1):38-40. doi: 10.3822/ijtmb.v3i1.78 [published Online First: 2010/01/01]

33. Stecco A, Stern R, Fantoni I, et al. Fascial Disorders: Implications for Treatment. PM R 2016;8(2):161-8. doi: 10.1016/j.pmrj.2015.06.006 [published Online First: 2015/06/17]

34. Casato G, Stecco C, Busin R. Role of fasciae in nonspecific low back pain. Eur J Transl Myol 2019;29(3):8330. doi: 10.4081/ejtm.2019.8330 [published Online First: 2019/10/04]

35. Bordoni B, Zanier E. Clinical and symptomatological reflections: the fascial system. J Multidiscip Healthc 2014;7:401-11. doi: 10.2147/JMDH.S68308 [published Online First: 2014/09/27]

36. Navot S, Kalichman L. Hip and groin pain in a cyclist resolved after performing a pelvic floor fascial mobilization. J Bodyw Mov Ther2016;20(3):604-9. doi: 10.1016/j.jbmt.2016.04.005

37. Langevin HM, Fox JR, Koptiuch C, et al. Reduced thoracolumbar fascia shear strain in human chronic low back pain. BMC Musculoskeletal Disorders 2011;12(1):203. doi: 10.1186/1471-2474-12-203

38. Threlkeld AJ. The effects of manual therapy on connective tissue.Phys Ther 1992;72(12):893-902. doi: 10.1093/ptj/72.12.893 [published Online First: 1992/12/01]

39. Cyr LM, Ross RG. How controlled stress affects healing tissues. Journal of Hand Therapy 1998;11(2):12530. doi: 10.1016/s0894-1130(98)80009-4

40. Harper B, Steinbeck L, Aron A. Fascial manipulation vs. standard physical therapy practice for low back pain diagnoses: A pragmatic study. J Bodyw Mov Ther 2019;23(1):115-21. doi: 10.1016/j.jbmt.2018.10.007 [published Online First: 2019/01/30]

41. Tozzi P, Bongiorno D, Vitturini C. Fascial release effects on patients with non-specific cervical or lumbar pain. J Bodyw Mov Ther 2011;15(4):405-16. doi: 10.1016/j.jbmt.2010.11.003 [published Online First: 2011/09/29]

42. Salvesen KA, Morkved S. Randomised controlled trial of pelvic floor muscle training during pregnancy. BMJ 2004;329(7462):378-80. doi: 10.1136/bmj.38163.724306.3A

43. Urbaniak G. C. PS. Research Randomizer 4.0 ed, 2013. 
44. Resende APM, Petricelli CD, Bernardes BT, et al. Electromyographic evaluation of pelvic floor muscles in pregnant and nonpregnant women.International Urogynecology Journal 2012;23(8):1041-45. doi: $10.1007 / \mathrm{s} 00192-012-1702-6$

45. Da Roza T, Mascarenhas T, Araujo M, et al. Oxford Grading Scale vs manometer for assessment of pelvic floor strength in nulliparous sports students. Physiotherapy 2013;99(3):207-11. doi: 10.1016/j.physio.2012.05.014

46. Gameiro MO, Sousa VO, Gameiro LF, et al. Comparison of pelvic floor muscle strength evaluations in nulliparous and primiparous women: a prospective study. Clinics (Sao Paulo) 2011;66(8):1389-94. doi: $10.1590 / \mathrm{s} 1807-59322011000800014$

47. Martinez Franco E, Pares D, Lorente Colome N, et al. Urinary incontinence during pregnancy. Is there a difference between first and third trimester? Eur J Obstet Gynecol Reprod Biol 2014;182:86-90. doi: 10.1016/j.ejogrb.2014.08.035

48. Davenport MH, Nagpal TS, Mottola MF, et al. Prenatal exercise (including but not limited to pelvic floor muscle training) and urinary incontinence during and following pregnancy: a systematic review and meta-analysis. Br J Sports Med 2018;52(21):1397-404. doi: 10.1136/bjsports-2018-099780

49. Schreiner L, Crivelatti I, de Oliveira JM, et al. Systematic review of pelvic floor interventions during pregnancy. Int J Gynaecol Obstet 2018;143(1):10-18. doi: 10.1002/ijgo.12513

50. Papageorghiou AT, Yu CK, Nicolaides KH. The role of uterine artery Doppler in predicting adverse pregnancy outcome. Best Pract Res Clin Obstet Gynaecol 2004;18(3):383-96. doi: 10.1016/j.bpobgyn.2004.02.003

51. Chan FY, Pun TC, Khoo J, et al. Pregnancy Screening by Uterine Artery Doppler Velocimetry - Which Criterion Performs Best?Obstetrics 83 Gynecology 1995;85(4):596-602. doi: 10.1016/0029-7844(95)00006-d

52. Arrue M, Garcia M, Rodriguez-Bengoa MT, et al. Do low-risk nulliparous women with abnormal uterine artery Doppler in the third trimester have poorer perinatal outcomes? A longitudinal prospective study on uterine artery Doppler in low-risk nulliparous women and correlation with pregnancy outcomes. The journal of maternal-fetal \& neonatal medicine : the official journal of the European Association of Perinatal Medicine, the Federation of Asia and Oceania Perinatal Societies, the International Society of Perinatal Obstet2017;30(7):877-80. doi: 10.1080/14767058.2016.1190822

53. Okido MM, Valeri FL, Martins WP, et al. Assessment of foetal wellbeing in pregnant women subjected to pelvic floor muscle training: a controlled randomised study. Int Urogynecol J2015;26(10):1475-81. doi: 10.1007/s00192-015-2719-4

54. Aran T, Pekgoz I, Bozkaya H, et al. Association between preterm labour and pelvic floor muscle function. J Obstet Gynaecol2018;38(8):1060-64. doi: 10.1080/01443615.2018.1446922

55. Vu D, Haylen BT, Tse K, et al. Surgical anatomy of the uterosacral ligament. Int Urogynecol $J$ 2010;21(9):1123-8. doi: 10.1007/s00192-010-1147-8

56. B CG. The Female Pelvis. Seattle: Eastland Press Inc. 2003.

57. Buscemi A, Petralia MC, Ramaci T, et al. Ergojump evaluation of the explosive strength in volleyball athletes pre- and post-fascial treatment. Exp Ther Med 2019;18(2):1470-76. doi: 10.3892/etm.2019.7628 [published Online First: 2019/08/07]

\section{Hosted file}

Figure 1 PFFM vs PFMT.docx available at https://authorea.com/users/349846/articles/474836the-influence-of-pelvic-floor-fascial-manual-mobilization-in-multiparous-women-arandomized-controlled-trial

\section{Hosted file}


Figure 2 PFFM vs PFMT.docx available at https://authorea.com/users/349846/articles/474836the-influence-of-pelvic-floor-fascial-manual-mobilization-in-multiparous-women-arandomized-controlled-trial

\section{Hosted file}

Figure 3 PFFM vs PFMT.docx available at https://authorea.com/users/349846/articles/474836the-influence-of-pelvic-floor-fascial-manual-mobilization-in-multiparous-women-arandomized-controlled-trial

\section{Hosted file}

Figure 4 PFFM vs PFMT.docx available at https://authorea.com/users/349846/articles/474836the-influence-of-pelvic-floor-fascial-manual-mobilization-in-multiparous-women-arandomized-controlled-trial

\section{Hosted file}

Figure 5 PFFM vs PFMT.docx available at https://authorea.com/users/349846/articles/474836the-influence-of-pelvic-floor-fascial-manual-mobilization-in-multiparous-women-arandomized-controlled-trial

\section{Hosted file}

Table 1 PFFM vs PFMT.docx available at https://authorea.com/users/349846/articles/474836-theinfluence-of-pelvic-floor-fascial-manual-mobilization-in-multiparous-women-a-randomizedcontrolled-trial

\section{Hosted file}

Table 2 PFFM vs PFMT.docx available at https://authorea.com/users/349846/articles/474836-theinfluence-of-pelvic-floor-fascial-manual-mobilization-in-multiparous-women-a-randomizedcontrolled-trial

\section{Hosted file}

flow chart.docx available at https://authorea.com/users/349846/articles/474836-theinfluence-of-pelvic-floor-fascial-manual-mobilization-in-multiparous-women-a-randomizedcontrolled-trial 